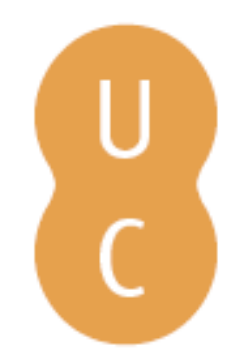

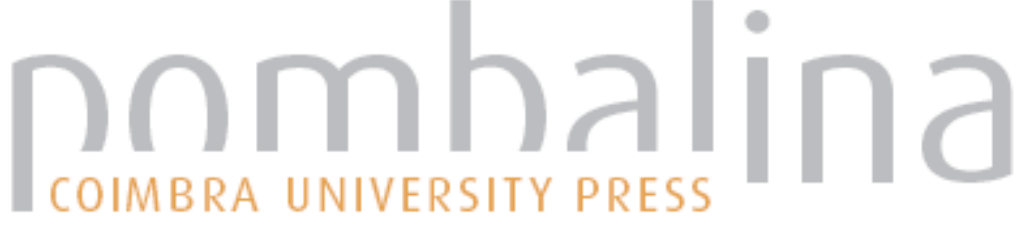

\section{Bártholo Thumann do Valle Pereira uma vida dedicada à cirurgia}

Autor(es): $\quad$ Pereira, Sofia do Vale; Pereira, Ricardo Vale

Publicado por: Imprensa da Universidade de Coimbra

URL

persistente: URI:http://hdl.handle.net/10316.2/32438

DOI: $\quad$ DOI:http://dx.doi.org/10.14195/978-989-26-0469-5_29

Accessed : $\quad$ 26-Apr-2023 16:29:48

A navegação consulta e descarregamento dos títulos inseridos nas Bibliotecas Digitais UC Digitalis, UC Pombalina e UC Impactum, pressupõem a aceitação plena e sem reservas dos Termos e Condições de Uso destas Bibliotecas Digitais, disponíveis em https://digitalis.uc.pt/pt-pt/termos.

Conforme exposto nos referidos Termos e Condições de Uso, o descarregamento de títulos de acesso restrito requer uma licença válida de autorização devendo o utilizador aceder ao(s) documento(s) a partir de um endereço de IP da instituição detentora da supramencionada licença.

Ao utilizador é apenas permitido o descarregamento para uso pessoal, pelo que o emprego do(s) título(s) descarregado(s) para outro fim, designadamente comercial, carece de autorização do respetivo autor ou editor da obra.

Na medida em que todas as obras da UC Digitalis se encontram protegidas pelo Código do Direito de Autor e Direitos Conexos e demais legislação aplicável, toda a cópia, parcial ou total, deste documento, nos casos em que é legalmente admitida, deverá conter ou fazer-se acompanhar por este aviso. 
Ana Leunar Pereira João Rui Pita

[ Coordenaçä̃ ]
Rotas da Natureza

Cientistas

Viagens

Expedifgũes

Instituip̧ües

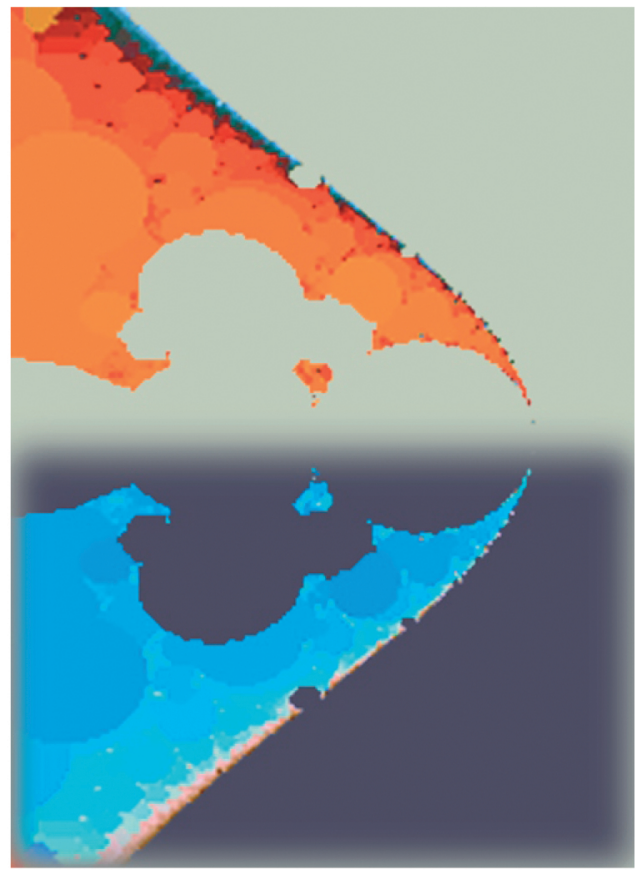




\section{Coordenaçáo Científica da Colecção Ciências e Culturas}

João Rui Pita e Ana Leonor Pereira

Os originais enviados são sujeitos a apreciação científica por referees

\section{Coordenação Editorial}

Maria João Padez Ferreira de Castro

\section{Edição}

Imprensa da Universidade de Coimbra

Email:impresauc@ci.uc.pt

URL: http://www.imp.uc.pt • Normas de publicação de colecçôes

\section{Design}

António Barros

Pré-Impressáo

António Resende

Imprensa da Universidade de Coimbra

\section{Capa}

António Barros, com imagem de E. M. de Melo e Castro, 2003 [Fractal original gerado no Fractint com tratamento no Photoshop 7.0]; Cortesia: António Barros

Impressão e Acabamento

SerSilito • Maia

\section{ISBN}

978-989-8074-12-6

\section{Depósito Legal}

Obra publicada com a colaboraçáo de:
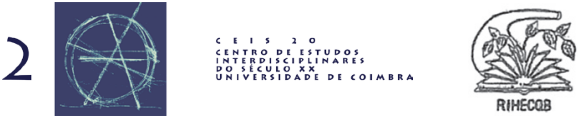

Obra publicada com o apoio de:

FCT Fundação para a Ciência e a Tecnologia

MINISTÉRIO DA CIÊNCIA, TECNOLOGIA E ENSINO SUPERTOR Portug

Programa Operacional Ciência, Tecnologia, Inovação do Quadro Comunitário de Apoio III
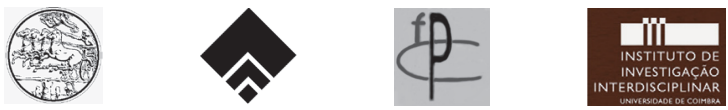

\section{Baxter}

(c) 2006, Imprensa da Universidade de Coimbra 
João Rui Pita

Ana Leonar Pereira

(Courdenação)

Rotas da Natureza

Cientistas

Viagens

Expediçũes

Instituiç̃̃es

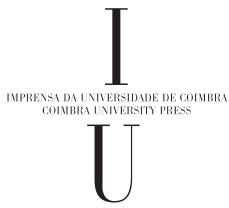

- colmbra 2006 
(Página deixada propositadamente em branco) 
Sofia do Vale Pereira* e Ricardo Vale Pereira**

* Bióloga, Portugal

** Médico especialista em Angiologia e Cirurgia Vascular, Portugal

\section{Bártholo Thumann do Valle Pereira UMA VIDA DEDICADA À CIRURGIA}

«Surgery is not only a craft, not only a science, not only an art, but something of all these, and therein lies its fascination»

«The Surgeon’s Craft», H. Atkins

Bártholo Thumann do Valle Pereira nasceu no Porto a 25 de Maio de 1918, filho de pai português e mãe alemã, que lhe incutiu o gosto pela música e pelas artes. Matriculou-se na Faculdade de Medicina da Universidade do Porto em 1936, tendo concluído a licenciatura em 1941 com a média final de 17 valores.

A sua escolha pela Cirurgia não foi difícil pois desde tenra idade mostrou interesse pelo estudo da anatomia de vários animais usando um estojo de dissecção, saciando assim a sua curiosidade e avidez por conhecimentos e esclarecimentos acerca da natureza do Homem e da Vida; aliado a isto, também uma ambição de auto-afirmação, prestígio e um sentimento de poder ser útil e agradável ao seu semelhante, o levaram a abraçar esta profissão.

Tendo como objectivo dedicar-se ao estudo e especialização em Cirurgia obteve uma bolsa de estudo da Alexander von Humboldt-Stiftung para trabalhar em Heidelberg, na Alemanha com o Professor Kirschner, o que não aproveitou por ter sido chamado a cumprir o serviço militar.

Três meses após a licenciatura foi convidado para $2^{\circ}$ Assistente da Cadeira de Fisiologia Especial (Professor Doutor Hernâni Monteiro), da Faculdade de Medicina do Porto, lugar que tomou posse em Maio de 1942. Acompanhou no entanto o Professor de Clínica Cirúrgica (Professor Doutor Álvaro Rodrigues) a partir de 1943, colaborando na realização de diversas intervenções e investigações nas áreas de Anatomia, Fisiologia e Anatomia Patológica. Em 1942 foi nomeado Assistente Voluntário de Propedêutica Cirúrgica, tendo transitado no ano seguinte, e também como Assistente Voluntário, para a Cadeira de Clínica Cirúrgica, da Faculdade de Medicina da Universidade do Porto. 
Em 1946, prestou provas de Doutoramento, com uma dissertação intitulada «Embolia Pulmonar», tendo sido aprovado por unanimidade com a classificação de 19 valores, após o que tomou posse do lugar de $1^{\circ}$ Assistente de Fisiologia Especial e, em Maio de 1948, passou a desempenhar as funçôes de $1^{\circ}$ Assistente de Clínica Cirúrgica.

Após o seu Doutoramento realizou vários estágios e cursos de especialização em Portugal e no Estrangeiro contactando com mestres de maior prestígio da época, junto dos quais ampliou a sua bagagem científica especializada: em Barcelona com Puig Sureda e Soler-Roig (Cirurgia Digestiva e do Esófago); no Reino Unido, durante um ano, onde trabalhou no Brompton Hospital com Sir Clement, Mr. Price-Thomas, Mr. Russel Brock, Mr. Barrett e Mr. Cleland (Cirurgia Cardíaca e Pulmonar) e Mr. Gabriel, Mr. Normand Tanner e Mr. Alisson em Leeds (Cirurgia do Aparelho Digestivo, Cólon e Recto e Esófago); na Alemanha com Professor Bauer de Heidelberg e Professor Derra de Düsseldorf, na Suécia com Professor Crafoord de Estocolmo e em França com Professor Santy e Professor Mallet-Guy de Lyon. Durante esta fase da sua carreira pode beneficiar de bolsas de estudos de Instituiçôes de renome, das quais se destacam Alexander von Humboldt-Stiftung, Instituto para a Alta Cultura, Bristish Council e Royal Society of Medicine.

Ao regressar ao Porto efectuou as primeiras esofagectomias e iniciou, na Faculdade de Medicina, a Cirurgia Cardíaca com a primeira comissurotomia mitral fechada efectuada em Portugal e operação de Blalock, procurando constituir uma equipa de Cirurgia Cardíaca, com instrumental que o próprio adquiriu em Inglaterra para esse propósito. Esse material foi entregue posteriormente ao Museu do Serviço de CárdioTorácica dos Hospitais da Universidade de Coimbra.

No período em que permaneceu no Porto desenvolveu intensa actividade assistencial na mesma cidade e região norte, realizando inúmeras intervençôes cirúrgicas na Faculdade de Medicina, em Hospitais e Ordens Religiosas, incidindo em quase todos os sectores da Cirurgia Geral e da Cirurgia Torácica destacando-se os seguintes factos:

- Em 1952 foi nomeado Cirurgião do Hospital Sub-regional de Amarante e, em 1954, Cirurgião do Hospital de Arnoia, em Celorico de Basto.

- Em 1955 foi nomeado Cirurgião do Centro de Cirurgia Torácica da Zona Norte, do Instituto da Assistência Nacional aos Tuberculosos (Sanatório de D. Manuel II).

- Em Junho de 1957 presta provas de habilitação ao título de Professor Agregado, na Faculdade de Medicina da Universidade do Porto.

- Em 1957, convidado pelo Professor Doutor Vaz Serra, concorreu a uma vaga de Professor Extraordinário do grupo de Cirurgia da Faculdade de Medicina da Universidade de Coimbra. Na sequência desse mesmo concurso foi nomeado Professor Extraordinário de Cirurgia dessa Faculdade, assumindo assim o cargo de Director do Serviço e Regente da Cadeira de Patologia Cirúrgica e, posteriormente, do Serviço de Clínica Cirúrgica dos Hospitais da Universidade de Coimbra.

- Em 1959, presta provas para Professor Catedrático da Faculdade de Medicina de Coimbra. No serviço que dirigiu até à sua jubilação, em 1988, criou a Cirurgia Plástica e Reconstrutiva e a Cirurgia Cardio-Torácica, tendo, no entanto, já realizado em 1957 a primeira correcção de uma coartação da aorta em Portugal. Iniciou, em 1976, a Cirurgia de Coração aberto. 
Várias outras técnicas Cirúrgicas foram por si introduzidas em Coimbra tais como: Pericardiectomia, Correcção da Persistência do Canal Arterial, Ressecção Pulmonar, a Esofagocoloplastia, Cirurgia da Hipertensão Portal (nomeadamente a Anastomose Porto-Cava), Duodenopancreatectomia, Exérese Pancreática, Ressecção Anterior do Recto ou mesmo a Cirurgia das Glândulas Supra-Renais.

Foi autor de inúmeros artigos e publicações, presidente e membro de direcção de diversas Sociedades de Cirurgia; recebeu, em nome da Faculdade de Medicina da Universidade de Coimbra, personalidades internacionais importantes do campo da Cirurgia como o Professor Christian Barnard, pioneiro na transplantação cardíaca mundial. Foi padrinho de doutoramento Honoris Causa de outro cirurgiáo cardíaco de renome, o Professor Doutor Zerbinni de São Paulo, Brasil.
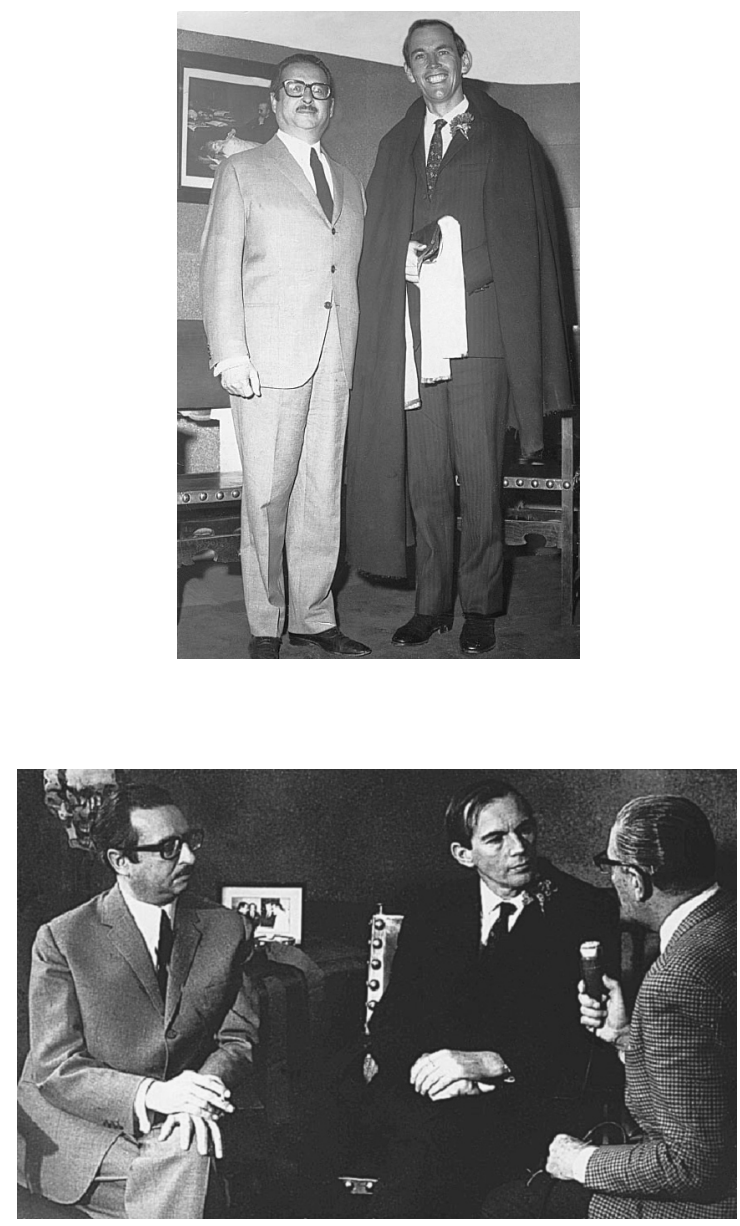

Visita e conversa televisionada com o Professor Christian Barnard, Coimbra 1968 
Formou e influenciou uma geração de cirurgiōes, procurando escolher como assistentes aqueles que considerou melhores e mais bem dotados para que pudessem ser continuadores, tendo alguns ascendido ao grau de doutor e professor e que também esses, alcançaram importância e relevo na cirurgia portuguesa.

Cremos que a actividade deste Professor e Cirurgião deixou marcas profundas e avanços, na Medicina e Cirurgia Portuguesas, não só pelo seu carácter técnico-científico-cultural, mas também pelas suas qualidades éticas e humanas, testemunhado pelos seus inúmeros doentes e discípulos.

Permitimo-nos assim citar as palavras do seu último doutorado: «Não é difícil imaginar os reflexos da sua prática na Cirurgia Portuguesa. São credores de uma gratidão perene os seus inúmeros doentes e todos os seus colaboradores. (...) Mas não foi só a excelência das suas qualidades científicas e técnicas que justificam a admiração de todos que com ele trabalharam. É o exemplo de um homem justo, tolerante, compreensivo, de pensamento liberal, com uma visão holística do seu serviço e transparentemente aberto às capacidades criativas de todos os seus discípulos. É também o exemplo da dimensão ética da sua personalidade e do seu enraizado humanismo, que sempre se manifestou, seja ao nível das relações pessoais, seja na prática médica quotidiana ou nos avanços cirúrgicos que o condicionou à salvaguarda da vida do homem sempre considerado como irmão. Os seus discípulos jamais esquecerão o exemplo deste ilustre Professor e Cirurgião». Júlio Soares Leite. in Revista Portuguesa de Cirurgia; Ano 3, no 4.

\section{Agradecimentos}

À Professora Doutora Marília Dourado, o nosso obrigado pela sua sincera amizade e incentivo e pelo elo de ligação com este importante Grupo de Estudos da nossa Universidade CEIS20.

À nossa mãe, por todo o apoio e pela grande mulher que é... por saber ter força para enfrentar a vida nos momentos mais difíceis.

\section{BIBLIOGRAFIA}

Bartholo do Valle Pereira, "Curriculum vitae», 1959.

Bartholo Thumann do Valle Pereira, «Oração de Sapiência - A Cirurgia Cardíaca, seus Fundamentos, sua Evolução e seu Futuro» Separata de Coimbra Médica, Vol. 9 (nº 3), 1988, 135-145.

Bartholo do Valle Pereira, "Última Lição», Separata de Coimbra Médica, Vol. 9 (n 4), 1988.

Bartholo do Valle Pereira, "Lição de Abertura de Curso", Separata de Coimbra Médica, Fasc. IV (Abril), 1958.

Bartholo do Valle Pereira, "Aspectos da Cirurgia Geral e Torácica em Inglaterra», Separata do Jornal do Médico, XX (506) 569-579, (507) 614-627, 1952.

http://www.huc.min-saude.pt/huc5p.html

Júlio Soares Leite, "Página dos Antigos Presidentes - Bártholo do Valle Pereira», Revista Portuguesa de Cirurgia-Órgão Oficial da Sociedade Portuguesa de Cirurgia, Ano 3 (n 4), 1995, 11. 


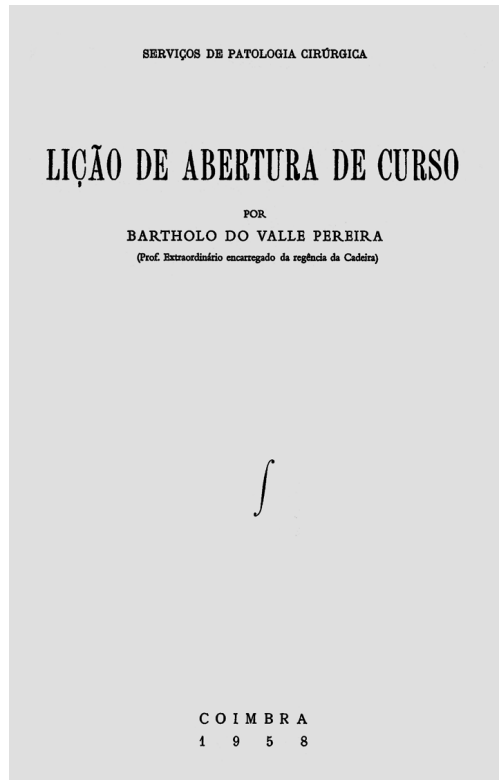

Bartholo do Valle Pereira

1.0 Assistente de Clinica Ciririrgica da Faculdade de Medicina do Porto

\section{Aspectos da cirurgia geral \\ e torácica em Inglaterra}

SEPARATA DO

Jorpal nprédico

XX (506) 569-579, (507) 614-627, 1952

$\begin{array}{llll}1 & 9 & 5 & 8\end{array}$

BARTHOLO THUMANN DO VALLE PEREIRA

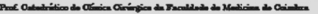

\section{ORAÇÃO DE SAPIÊNCIA}

A CIRURGIA CARDIACA, SEUS FUNDAMENTOS,

SUA EVOLUÇÃo E SEU FUTURO
BARTHOLO DO VALLE PEREIRA

\author{
Última lição
}

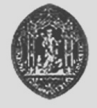

COIMBRA 


\section{Colecçãa \\ 2 Ciências e Culturas Caimbra 2006}

